Del referéndum a la secesión - El proceso quebequense de acceso a la soberanía y las lecciones aprendidas con respecto a la autodeterminación From referendum to secession - The Québécois process of accession to sovereignty and its teachings with respect to self-determination ${ }^{* * *}$

Dave Guénette

Université Laval, Québec y Université Catholique de Louvain, Louvain-la-Neuve dave.guenette.1@ulaval.ca

\author{
Alain-G. Gagnon \\ Université du Québec à Montréal \\ gagnon.alain@uqam.ca
}

Recibido / received: 26/05/2017

Aceptado / accepted: 15/07/2017

\title{
DOI: https://doi.org/10.20318/eunomia.2017.3803
}

\section{Resumen}

Como resultado de los dos referenda sobre la soberanía en 1980 y 1995, Quebec se ha convertido en un caso clave entre el resto de democracias occidentales. Se trata de un estado moderno desarrollado que intenta obtener su independencia, no en tiempo de guerra ni debido a una opresión política grave, ni con el fin de poner fin a una ocupación colonial de sus territorios o de liberarse de un sistema político antidemocrático, sino por razones que son, en primera instancia, culturales, identitarias, lingüísticas y económicas. En este sentido, y a pesar de la falta de éxito en los dos intentos de referéndum, la nación quebequense aún debe ser reconocida por su rol pionero en cuanto a reconocer el derecho a la secesión de las naciones minoritarias. Al adoptar este enfoque, este artículo se centra en el proceso quebequense de acceso a la soberanía y en las lecciones que puede mostrar, en este sentido, a una España multinacional.

\footnotetext{
* Traducción de Jorge San Vicente Feduchi.

${ }^{(* *}$ Este artículo toma como base una inédita versión inglesa del trabajo. Una parte del mismo, en su versión francesa, ha sido publicada en la Revista Catalana del Dret Públic, núm. 54 (juny 2017), p. 100-117.
} 


\title{
Palabras clave
}

Autodeterminación externa, naciones minoritarias, secesión, referéndum, Quebec, proceso soberanista catalán.

\begin{abstract}
As a result of the two referenda on sovereignty held in 1980 and 1995, Quebec has somehow become something of a figurehead for western democracies. It represents a modern developed state seeking national independence, not in time of war or because of serious political oppression, or to end colonial dependence in its territory or rid itself of an antidemocratic political system, but rather and above all by taking this path for cultural, identity, linguistic and economic reasons. In this regard, and notwithstanding the fact that both referenda failed to bring independence, it is still fair to grant the Québéquois nation a pioneering role in terms of recognising the right of minority nations to secede. In adopting this approach, this article looks at the Québéquois process of accessing sovereignty and the lessons that it can offer, in this regard, to a multinational Spain.
\end{abstract}

\section{Keywords}

External self-determination, minority nations, secession, referendum, Quebec, Catalan sovereignty process.

\begin{abstract}
SUMARIO. 1. La capacidad constitucional de las instituciones del Quebec para celebrar una consulta popular - Una apuesta poco debatida y poco confrontada. 1.1. La dimensión histórica que desembocó en las consultas populares sobre la soberanía del Quebec. 1.1.1. Prácticas de referéndum en Quebec y Canadá previas a los debates sobre la secesión. 1.1.2. Los referenda de 1980 y 1995 sobre la soberanía del Quebec. 1.2. Aspectos legales que permiten los referenda de autodeterminación en Canadá. 1.2.1. La ausencia de restricciones constitucionales positivas para la celebración de un referéndum. 1.2.2. Prácticas constitucionales relativas a la consulta popular. 2. Capacidades constitucionales del Quebec para declarar su independencia - Una cuestión sobre la que hay menos consenso. 2.1. El activismo de las instituciones federales. 2.1.1. La Decisión relativa a la Secesión del Quebec y la reconciliación de intereses altamente divergentes por parte de la Corte Suprema de Canadá. 2.1.2. La Ley de Claridad y la declaración del Parlamento Federal de que era tanto parte como juez en disputas constitucionales. 2.2. La evolución contemporánea del debate y cuestiones en suspenso. 2.2.1. El umbral de la mayoría popular requerida para que Quebec declare su independencia. 2.2.2. La ambigüedad procesal en torno a la obligación de negociar y al proceso de control de constitucionalidad pertinente. 3. Discusión y conclusión - Quebec y Cataluña: casos comparables significativos en contextos políticos y constitucionales muy diferentes.
\end{abstract}

Durante los últimos 50 años, el debate sobre la capacidad del Quebec de declarar su independencia del resto de Canadá ha definido la vida política y constitucional del país. Desde la elección en 1976 del partido de René Lévesque, el Parti Québécois, hasta los referenda de 1980 y 1995, pasando por el Dictamen relativo a la Secesión del Quebec (Renvoi relatif à la sécession du Québec, 1998) y la Ley de Claridad (Loi donnant effet à l'exigence de clarté formulée par la Cour suprême du Canada dans son avis sur le Renvoi sur la sécession du Québec, 2000) del Parlamento Federal, la cuestión constitucional sobre la soberanía del Quebec ha formado parte del panorama político canadiense. 
Quebec, por tanto, ha sido un caso clave entre las democracias occidentales. Se trata de un estado moderno desarrollado que intenta obtener su independencia, no en tiempo de guerra ni debido a una opresión política grave, ni con el fin de poner fin a una ocupación colonial de sus territorios o de liberarse de un sistema político antidemocrático, sino por razones que son, en primera instancia, culturales, identitarias, lingüísticas y económicas. En este sentido, y a pesar de la falta de éxito en los dos intentos de referéndum, la nación quebequense aún debe ser reconocida por su rol pionero en la defensa del derecho a la autodeterminación externa de las naciones minoritarias, tanto desde el punto de vista académico como práctico.

Por un lado, desde una perspectiva académica, se ha escrito abundantemente sobre el derecho a la secesión de naciones minoritarias. La literatura científica no solo se refiere a la experiencia del Quebec, sino que se considera aplicable a otras regiones. Estos textos pueden ser divididos en dos categorías, dependiendo de si la apuesta por el derecho a la independencia en estados multinacionales es tratada de manera directa (Patten, 2002: 458; Weinstock, 2001: 182; Dumont y El Behroumi, 2017; Cagiao y Conde, 2016; Beaud, 2017), o de si el derecho a la autodeterminación se convierte en una opción formal que se debe tener en cuenta al analizar la convivencia (vivre-ensemble) en sociedades multinacionales ${ }^{1}$. Si bien no asumimos que el caso del Quebec es la fuente de toda esta literatura, se trata indudablemente de un punto de partida ineludible, que puede alimentar de varias maneras nuestras reflexiones.

Por otro lado, desde un punto de vista práctico, desde los referenda sobre la soberanía-asociación (souveraineté-association) en 1980 y la soberaníacoparticipación (souveraineté-partenariat) en 1995, otras naciones minoritarias en contextos políticos similares también han dado pasos hacia la secesión. Naturalmente, vienen a la mente casos como el de Escocia, donde tuvo lugar un referéndum de autodeterminación en 2014, y el de Cataluña, donde se organizó una consulta popular sobre la independencia en el mismo año, seguida de una elecciónreferéndum sobre la misma cuestión en 2015. En Cataluña se está planeando en estos momentos un referéndum formal sobre la independencia, que tendría lugar en octubre de 2017. En su largo camino hacia la soberanía, tanto los escoceses como los catalanes se han inspirado en el proceso quebequense y han tratado de aprender tanto de sus éxitos como de los obstáculos que se han encontrado (Bérard, 2015; Rocher y Casanas Adams, 2015: 877; Beauséjour, 2015).

Por estas razones, la experiencia del Quebec y el proceso -aún por terminar- de acceso a su soberanía debe tenerse en cuenta. A pesar de ello, mientras los movimientos secesionistas en Escocia y Cataluña se ven inevitablemente inspirados por esa experiencia, éstos también aportan información valiosa al debate, no solo en lo que se refiere a la soberanía de Quebec, sino también más ampliamente respecto al derecho de autodeterminación de naciones minoritarias dentro de sociedades multinacionales democráticas.

Indudablemente, las lecciones aprendidas del Quebec, Escocia y Cataluña -así como, posiblemente, de experiencias como las de los flamencos o los surtiroleses- comparten fuertes similitudes y contribuyen a una muestra más representativa de procesos de autodeterminación de naciones minoritarias en contextos multinacionales. Todos participan en una forma de diálogo dinámico en el que la experiencia práctica de uno de ellos puede tener una influencia concreta y evidente en los debates internos de otros movimientos separatistas e independentistas.

\footnotetext{
${ }^{1}$ Véase, por ejemplo, Mathieu y Guénette (próximo), en el cual los autores califican al derecho de autodeterminación externa como uno de sus seis pilares socio-culturales.
} 
Teniendo en cuenta esta observación, el proceso de acceso a la independencia del Quebec es, tanto cronológica como sustancialmente, un punto de referencia con respecto a dos dimensiones fundamentales distintas (pero complementarias). En efecto, dadas las experiencias escocesa y catalana, creemos que es útil dividir las lecciones del caso quebequense de acuerdo a si se relacionan a (1) la capacidad constitucional de las instituciones del Quebec para celebrar una consulta popular o a (2) la capacidad del Quebec de declarar su independencia del resto de Canadá. Ambas dimensiones serán los sujetos del presente estudio.

1. La capacidad constitucional de las instituciones del Quebec para celebrar una consulta popular - Una apuesta poco debatida y poco confrontada

Tal y como se ha visto en los procesos independentistas de Escocia y Cataluña, la capacidad constitucional de una nación minoritaria de celebrar una consulta popular dentro de sus fronteras no debería darse por sentada. Mientras en Escocia la celebración del referéndum tuvo que ser previamente aprobada por el Gobierno británico en el Acuerdo de Edimburgo (Agreement between the United Kingdom Government and the Scottish Government on a referendum on independence for Scotland, 2012), en Cataluña, tanto el Gobierno español como el Tribunal Constitucional se oponen firmemente a garantizar esa posibilidad a la comunidad autónoma ${ }^{2}$. Por tanto, parece esencial discutir la capacidad constitucional de las instituciones del Quebec para celebrar una consulta popular. Para ello, nos detendremos en (1.1) la dimensión histórica y (1.2) legal que autorizó los referenda de autodeterminación en Canadá.

1.1. La dimensión histórica que desembocó en las consultas populares sobre la soberanía del Quebec

Para entender el contexto de los referenda de independencia del Quebec, así como su fundamento legal, debemos primero examinar (1.1.1) la historia de prácticas de consulta popular en Quebec y en Canadá previa a los debates sobre la secesión, y después centrarnos en (1.1.2) los referenda de 1980 y 1995 sobre la soberanía del Quebec.

1.1.1. Prácticas de referéndum en Quebec y Canadá previas a los debates sobre la secesión

Los principales pilares de la capacidad del Quebec para celebrar consultas públicas dentro de sus fronteras tienen sus raíces en prácticas que datan de 1867, en la provincia y en el resto de Canadá. En efecto, "debido a razones históricas y contextuales, los referenda en general, y el derecho del Quebec de elegir su estatus político en particular, se han llevado a cabo, de facto, liberados, en gran parte, del mecanismo institucional establecido en la constitución formal" (Taillon, 2016: 265, 269-270) ${ }^{3}$. Así, puede observarse cómo mucho antes de que existiese el debate sobre la posibilidad de celebrar un referéndum sobre la independencia del Quebec, ya existían en Canadá prácticas de democracia directa. Tanto legal como políticamente, las bases de la capacidad del Quebec de celebrar una consulta popular estaban establecidas.

Para empezar, debemos destacar que los plebiscitos han sido relativamente anómalos, tanto a nivel nacional como provincial. Como han puntualizado los juristas

\footnotetext{
${ }^{2}$ Véase, por ejemplo, S.T.C. 31/2015, BOE No. 64 , p. 190 y S.T.C. $32 / 2015$, BOE No. 64 , p. 213.

${ }^{3}$ Traducción propia.
} 
Henri Brun, Guy Tremblay y Eugénie Brouillet (2014: 98): "En los regímenes constitucionales inspirados por el modelo británico es generalmente poco común observar técnicas derivadas de la democracia directa"4. Dado que este tipo de prácticas no se han utilizado comúnmente en el sistema político canadiense, aquellas no están muy institucionalizadas o sujetas a reglas claras como, por ejemplo, en Suiza.

Históricamente, se han celebrado referenda en Canadá en 1899 —sobre la ley seca (Directeur Genéral des Elections du Quebec, 2012: 14) - y en 1942 sobre el servicio militar (ibídem: 15) - . Un tercer referéndum pan-canadiense también tuvo lugar en 1992 para consultar al pueblo sobre el Acuerdo de Charlottetown ${ }^{5}$. Se han celebrado así un total de tres consultas populares en Canadá durante sus primeros 150 años de existencia. Incluso hoy, Canadá solo tiene una "ley de Referéndum limitado" (Marquis, 1993) referente a los plebiscitos, la Loi concernant les référendums sur la Constitution du Canada ${ }^{6}$. Esto muestra el bajo grado de institucionalización de las prácticas de consulta popular. Consecuentemente, existe cierta ambigüedad en el proceso de referéndum en Canadá con respecto a sus fundamentos legales, así como a su organización y a la interpretación de sus resultados (Guénette, 2018) ${ }^{7}$.

Un fenómeno similar puede observarse en el nivel provincial, a pesar de que allí estas prácticas han sido un poco más comunes (Marquis, 1993). Por ejemplo, "Saskatchewan, Manitoba y Alberta adoptaron legislación sobre referenda a principios del siglo XX" (Brun, Tremblay y Brouillet, 2014: 98) ${ }^{8}$ para estructurar las prácticas de democracia directa. Por otra parte, algunas provincias supeditan la aprobación de enmiendas a la constitución a la celebración previa de un referéndum provincial (Constitutional Amendment Approval Act, 1996; Constitutional Referendum Act, 1992). Es más, la gran mayoría de provincias hoy en día "tienen una disposición para la celebración de un plebiscito" (Marquis, 1993).

En el caso del Quebec, se han celebrado cuatro referenda provinciales (Directeur Genéral des Elections du Quebec, 2017) hasta la fecha. El primero, en 1919 y referente a la ley seca, fue posible "gracias a una ley especial" (Brun, Tremblay y Brouillet, 2014: 98). Estableció por tanto un precedente importante, aunque en el momento Quebec no tenía un marco legal establecido que gobernase sus propias prácticas de democracia directa. Hubo que esperar 50 años para que un proyecto de ley promovido por la Union Nationale, que en ese momento era el partido en el poder en la Asamblea Nacional de Quebec, propusiera el establecimiento de un marco legal para las consultas públicas (ibídem: 98). Abandonado por el Gobierno liberal que sucedió a Union Nationale, esa ley no se adoptó hasta 1978, bajo el gobierno del partido independentista Parti Québécois (ibíd.: 98). Este fue el marco legal para los tres referenda sucesivos en Quebec, incluyendo los del 1980 y 1995 referentes a la soberanía de la provincia ${ }^{9}$.

\footnotetext{
${ }^{4}$ Traducción propia.

${ }^{5}$ Volveremos a este referéndum en las secciones 1.1.2 y 1.2.2 para analizar con mayor detalle como contribuyó recordando la capacidad constitucional de Quebec en términos de consulta popular.

${ }^{6}$ Como su propio nombre indica, esta ley puede ser utilizada únicamente para proveer de un marco a un referéndum en la Constitución; su vocación, por tanto, no es para gobernar todas las acciones de democracia directa en Canadá.

${ }^{7}$ Traducción propia.

${ }^{8}$ Traducción propia.

9 El tercer referéndum en Quebec llevado a cabo en 1980 es el del Acuerdo de Charlottetown. Aunque fue una consulta pan-canadiense, el Gobierno de Quebec insistió (y lo consiguió) en que fuera llevado a cabo bajo una Ley de Referéndum. Formalmente, por tanto, dos referéndums fueron llevados a cabo en el mismo día.
} 
Si algo podemos aprender de las prácticas de referéndum en Quebec y Canadá, incluso de las anteriores al debate sobre la secesión, es que, a pesar de su relativa poca frecuencia, y a pesar de la falta de un marco legal y constitucional formal para llevarlas a cabo, recurrir a esta herramienta democrática es aún posible para actores políticos tanto a nivel provincial como del Gobierno central. Ahora ya podemos dirigir nuestra atención al estudio de los referenda sobre la independencia del Quebec.

\subsubsection{Los referenda de 1980 y 1995 sobre la soberanía del Quebec}

Hasta la década de 1980, los quebequenses tan solo habían votado en tres referenda, en 1898, 1919 y 1942. A pesar de ello, entre 1966 y 1977, la idea de que "un referéndum pudiese resolver el eterno debate constitucional volvía a salir a la luz de tiempo en tiempo" (Directeur Genéral des Elections du Quebec, 2012: 26). El enfoque político de dar forma a la autodeterminación externa, inspirada por la victoria del Gobierno de René Lévesque en 1976, se materializó en la Ley de Referéndum del 23 de junio de 1978 (ibídem: 27), la cual permitió la celebración del primer referéndum sobre la soberanía de Quebec el 20 de mayo de 1980.

Entonces, Quebec votó la propuesta del gobierno provincial sobre una "soberanía-asociación". El resultado, aunque no fuese el esperado por las fuerzas independentistas, tuvo el mérito de permitir a los quebequenses pronunciarse sobre su futuro político y constitucional. Tras una campaña de 35 días, el 59,56 \% de los quebequenses votaron en contra de la independencia, mientas que el $40,44 \%$ apoyó la propuesta independentista en una votación que alcanzó el 85,61 \% de participación (Brun, Tremblay y Brouillet, 2014: 113).

Sin embargo, más allá de los resultados, el foco de nuestra atención debería ser el proceso de referéndum, ya que el Gobierno del Quebec pudo actuar independiente y autónomamente, sin necesidad de consultar ni pedir autorización de Ottawa. Formalmente, el proceso fue llevado a cabo dentro del Quebec, a través de sus propias instituciones. Comenzó con un debate que se extendió hasta las 36 horas, repartidas en 17 días, en la Asamblea Nacional, durante el cual todos los representantes de todas las orientaciones políticas tuvieron la oportunidad de expresar sus opiniones (Directeur Genéral des Elections du Quebec, 2012: 37-38). En la campaña que lo siguió, el líder del "Sí" fue René Lévesque, Primer Ministro de Quebec, y el del "No", Claude Ryan, líder de la Oposición Oficial en la provincia (ibídem: 39).

Una de las consecuencias de ese debate, formalmente organizado tan solo entre los actores políticos del Quebec, fue que el Gobierno central, aunque no se opusiera a la capacidad del Quebec de celebrar el referéndum, acabó imponiendo su postura y rechazó "ignorar el sistema de comités nacionales establecido en la Ley de Referendos" (Brun, Tremblay y Brouillet, 2014: 112) ${ }^{10}$. El Tribunal Superior del Quebec (Boucher v. Mediacom, 1980) y el Consejo del Referéndum (Boucher v. Mediacom, 1980) finalmente decidieron en su favor, permitiendo intervenir a actores de Ottawa en la campaña del referéndum sin prestar atención a las condiciones establecidas en la legislación adoptada en la Asamblea Nacional.

Se estableció, por tanto, un precedente significativo por el que el Gobierno del Quebec podía, de manera autónoma, celebrar un referéndum sobre la soberanía de la provincia a través de las instituciones locales y sin la autorización previa de Ottawa. Sin embargo, el Gobierno central podía por su parte adoptar la estrategia que desease y actuar como quisiese sin importar el marco legal del Quebec.

\footnotetext{
${ }^{10}$ Traducción propia.
} 
En línea con este precedente, desde un punto de vista procesal, el referéndum de 1995 tuvo mucho en común con el de 1980. Formalmente, se llevó a cabo entre actores del Quebec e incluyó un debate de 35 horas en la Asamblea Nacional y la formación de un bando del "Sí" liderado por el Primer Ministro del Quebec (Jacques Parizeau) y otro del "No" encabezado por el líder de la Oposición Oficial (Daniel Johnson) (Directeur Genéral des Elections du Quebec, 2012: 51). De nuevo, el Gobierno central rechazó suscribirse al marco legal del Quebec, pero no intentó bloquear la celebración del referéndum.

Fue, sin embargo, el propio resultado lo que diferenció a este referéndum del anterior. En 1995, la opción del "No" ganó estrechamente, con el 50,58 \% de los votos, ante el $49,42 \%$ de los votos a favor, con una participación que llegó esta vez hasta el 93,52 \% de los votantes registrados (ibídem: 56). La consecuencia de tal resultado fue alentar a las autoridades federales a cambiar sus estrategias en respuesta a la marcha de los quebequenses hacia la independencia ${ }^{11}$.

Tras este breve repaso histórico de la capacidad del Quebec de celebrar un referéndum sobre su futuro constitucional y político, debemos extraer algunas conclusiones. Para empezar, a pesar de la escasa presencia de prácticas de democracia directa en Canadá, ocasionalmente se han celebrado referenda sobre diversas cuestiones, tanto a nivel federal como provincial, desde que se firmó el pacto constitucional de 1867. Por tanto, si Quebec decidiese establecer un marco legal formal para una consulta popular con el fin de declarar su independencia, parece difícil, si no imposible, tratar de denegarle esa prerrogativa. Consecuentemente, los referenda de 1980 y 1995, así como los consecuentes debates, fueron llevados a cabo estrictamente en instituciones quebequenses. Sin embargo, el Gobierno central intervino a su propia manera en esas campañas, sin agachar la cabeza ante las leyes provinciales sobre la materia.

1.2. Aspectos legales que permiten los referenda de autodeterminación en Canadá

Cuando el camino hacia la independencia del Quebec comenzaba a acelerarse, no fueron solo los precedentes históricos los que parecían hacer posible la celebración de un referéndum interno, sino también su marco legal. La legislación constitucional de Canadá y su naturaleza escrita, consuetudinaria y convencional, así como sus dimensiones (en ocasiones) obsoletas y silenciosas, tuvieron consecuencias en el proceso de autodeterminación del Quebec. Por tanto, debemos evaluar la flexibilidad de las autoridades políticas con respecto a los referenda en el contexto constitucional específico de Canadá. El carácter especial del sistema constitucional canadiense requiere no solo una investigación sobre lo que está permitido en los textos, sino también en las fuentes no escritas de la Constitución. Con este fin, discutiremos (1.2.1) la ausencia de restricciones constitucionales para la celebración de un referéndum y (1.2.2) las prácticas de consulta popular.

1.2.1. La ausencia de restricciones constitucionales positivas para la celebración de un referéndum

En la Constitución escrita no se menciona ninguna herramienta de democracia directa. Como dice el jurista Patrick Taillon (2016: 270-271), "[d]esde el origen de la federación canadiense en 1867 hasta hoy, los textos de la Constitución canadiense no han aludido a la posibilidad de celebrar un referéndum: tanto en lo que se refiere a las enmiendas constitucionales como a la adopción de legislación federal y

${ }^{11}$ Volveremos a esto en la sección 2.1. 
provincial, los textos se basan estrictamente en una concepción representativa de la democracia". A pesar de que este vacío en los escritos no es ni mucho menos un caso aislado en la legislación constitucional canadiense (Guénette, 2015a: 411), tampoco prohíbe ni hace más difícil legalmente el uso de herramientas de consulta. En lo que a ello respecta, para evaluar la legalidad de las consultas populares bajo la legislación canadiense, debemos tomar en consideración no solo las disposiciones constitucionales que puedan informarnos sobre la cuestión, sino también la jurisprudencia generada a través de los años.

Primero, con respecto a las disposiciones constitucionales que pueden no referirse directamente a la posibilidad de celebrar un referéndum pero que pueden ser interpretadas para ello, existen tren secciones especialmente pertinentes. Siguiendo el razonamiento de Patrick Taillon, la sección 45 de la Ley Constitucional de $1982^{12}$-que establece la capacidad de cada provincia de enmendar unilateralmente su propia constitución-, la sección 92.16 de la Ley Constitucional de 1867 -que establece el poder legislativo de las provincias en "todas las Cuestiones de Naturaleza meramente local o privada en la Provincia" - y la sección 129 de la misma ley - que concierne a la continuidad de las normas legislativas en vigor anteriormente a la Confederación de 1867- probablemente reconocen que las provincias tienen las competencias para convocar un referéndum (Taillon, 2016: 274-275). En conjunto, estas disposiciones constituyen un fundamento jurídico sólido para certificar la legalidad de la consulta popular convocada por el Gobierno del Quebec.

Con respecto a la jurisprudencia, tanto el Comité Judicial del Consejo Privado en Londres como la Corte Suprema de Canadá —que se estableció en 1949 como el tribunal de última instancia- emitieron una decisión en la que aprobaban, en cierta medida, el recurso a mecanismos de referéndum. Para empezar, en 1919 (In re Initiative and Referendum Act, 1919) y en 1922 (R. v. Nat Bell Liquors Ltd., 1922), el Comité Judicial emitió una importante sentencia, cuyo resultado fue que las provincias pudieran "invocar la sección 45 [de la Ley Constitucional de 1982] para añadir ciertas herramientas de democracia directa al régimen parlamentario presente" (Pelletier, 1996: 167) ${ }^{13}$. Posteriormente, la Corte Suprema de Canadá confirmó esta interpretación al completo, notablemente en las decisiones Haig (Haig v. Canada, 1993: 995) y Libman (Libman v. Québec, 1997: 995), y aún más explícitamente en 1998, en el Dictamen relativo a la Secesión del Quebec. Sosteniendo de nuevo la validez de la Ley de Referéndum del Quebec, así como "la autoridad de las provincias de consultar a sus propios electores como vean conveniente" (ibídem: 1006), no solo dio por terminado el debate sobre la capacidad de los actores políticos de convocar el referéndum, sino también reiteró la legitimidad democrática de dichos procesos.

En este sentido, la ley canadiense no solo no contiene ninguna limitación positiva para la celebración de un referéndum, sino que además sus textos constitucionales, así como la jurisprudencia del Consejo Privado en Londres y de la Corte Suprema de Canadá, confirman la tesis de que la Constitución debe ser interpretada de tal manera que los plebiscitos sean permitidos. Como veremos más abajo, las prácticas constitucionales también apoyan este argumento.

\subsubsection{Prácticas constitucionales relativas a la consulta popular}

\footnotetext{
${ }^{12}$ Este artículo sustituyó al artículo 92.1 de la Constitución de 1867, pero no existe continuidad legal con él.

${ }^{13}$ Traducción propia.
} 
Paralelamente al texto de la Constitución y su jurisprudencia, ciertas prácticas también llevan a la conclusión de que debe ser posible, bajo la ley canadiense, celebrar una consulta popular. En efecto, "[a] pesar de que no fuese pretendido ni anticipado por los redactores de la Constitución, se han llevado a cabo referenda de manera paralela a la Constitución - gracias a una evolución en las prácticas políticas y se han consolidado gracias a su reconocimiento en la jurisprudencia" (Taillon, 2016: 290) ${ }^{14}$. Estos precedentes, que datan de antes de los debates sobre la secesión del Quebec, también contribuyen a establecer las bases de la legalidad sobre los referenda de soberanía en 1980 y 1995.

Como argumentábamos en el punto 1.1.1, anteriormente al debate sobre la secesión se llevaron a cabo referenda en Canadá, Quebec y en otras provincias, y se adoptó legislación al respecto en algunas provincias para proveer de un marco legal a las consultas populares. En conjunto, estas prácticas y estos mecanismos legislativos formaron un conjunto de precedentes que, aunque en el límite del mecanismo constitucional, constituyeron los primeros embriones de la democracia directa de Canadá. Ahora, estos forman parte de la cultura constitucional canadiense, y su legalidad no está abierta a debate cuando el Gobierno del Quebec anuncia su intención de convocar un referéndum sobre su soberanía.

Estos precedentes son altamente significativos. Una de las consecuencias de la naturaleza mixta, heterogénea y descentralizada del derecho constitucional canadiense es que un solo precedente puede tener un impacto real y tangible. Como dice el jurista Allan C. Hutchinson (2013, 51-53), la Constitución canadiense es "una mezcolanza de textos, costumbres, convenciones, ideales y casos". En este sentido, dada la naturaleza del constitucionalismo canadiense, es muy posible que, si las competencias del Quebec para convocar una consulta popular hubieran encontrado oposición, los precedentes legislativos y las prácticas pasadas, tanto a nivel federal como provincial, hubieran garantizado su celebración.

En resumen, el estudio de las dimensiones históricas y legales muestra que no hay ambigüedad con respecto al poder del Quebec de celebrar referenda de autodeterminación dentro de sus propias fronteras. Las prácticas históricas relativas a las consultas populares en Canadá, su estatus como precedentes constitucionales, la ausencia de oposición por parte del Gobierno central en 1980 y 1995 y el marco constitucional general constituyen, en conjunto, otro argumento a favor de esta interpretación. Es por ello que creemos que esta es una cuestión que no genera debate u oposición en Canadá. Sin embargo, la situación es distinta cuando hablamos de la posibilidad de que Quebec pueda declarar su independencia.

2. Capacidades constitucionales del Quebec para declarar su independencia Una cuestión sobre la que hay menos consenso

Dado que nunca ha habido una verdadera oposición a la posibilidad de que Quebec pudiese consultar a su población a través de un referéndum, los debates en Canadá se han centrado más en la capacidad del Quebec de declarar su independencia. Al menos desde los ajustados resultados en el referenda de 1995, (2.1) las instituciones federales han demostrado un grado de activísimo frente al camino hacia la independencia del Quebec. Uno de los efectos más notables de ese activismo ha sido (2.2) transformar el debate constitucional y plantear nuevas

\footnotetext{
${ }^{14}$ Traducción propia.
} 
cuestiones sobre las condiciones y los procedimientos que deberían ser respetados durante un proceso secesionista.

\subsection{EI activismo de las instituciones federales}

Tras el referéndum de 1995, en el cual los independentistas se quedaron a tan solo 50.000 votos de la mayoría absoluta, el Gobierno central reaccionó desde diferentes frentes. Como han puntualizado Henri Brun, Guy Tremblay y Eugénie Brouillet (2014: 116), "el hecho de que la opción soberanista se acercase tanto a la victoria incitó a las autoridades federales a replantear su posición estratégica" ${ }^{\prime 15}$. Aunque es cierto que demostró cierta apertura al recomendar que el Parlamento adoptara una moción que reconocía "el carácter distinto de la sociedad de Quebec" (Canadá, House of Commons, 1995: 16791) y al dar a la asamblea legislativa provincial la capacidad de veto sobre ciertas enmiendas constitucionales (Loi concernant les modifications constitutionnelles, 1996), el Gobierno central endureció su postura en lo relativo al proceso independentista. Como parte de su respuesta (2.1.1), su primera acción fue reclamar que la Corte Suprema de Canadá tomase una posición sobre la legalidad de la declaración de secesión del Quebec. Después de recibir una matizada respuesta, dirigió su atención al Parlamento canadiense, donde se adoptó la Ley de Claridad (2.1.2).

\subsubsection{El Dictamen relativo a la Secesión del Quebec y la reconciliación de intereses} altamente divergentes por parte de la Corte Suprema de Canadá

En la ley canadiense, hay un procedimiento que permite al poder ejecutivo consultar al poder judicial su opinión sobre asuntos legales o constitucionales. A nivel federal, la sección 53 de la Ley de la Corte Suprema es la que permite al Gobierno central preguntar sobre estas cuestiones a la corte más elevada. A pesar de que las opiniones de la Corte Suprema -y sus decisiones - son formalmente consultativas, estas tienen cierto grado de fuerza normativa y son tomadas en consideración por las autoridades políticas.

Es por tanto en virtud de este procedimiento que "en septiembre de 1996, el Gobierno federal preguntó a la Corte Suprema de Canadá" (Rocher y Casanas Adams, 2016: 899) ${ }^{16} \mathrm{si}$, bajo la legislación constitucional canadiense y la legislación internacional, Quebec podía proceder unilateralmente en un proceso de secesión del resto de Canadá. El Gobierno del Quebec, en su deseo de evitar dar legitimidad a un proceso en el que fuera una institución federal la que se pronunciase sobre el derecho del Quebec a declarar su independencia, decidió no participar en el debate en el Corte Suprema: "El Gobierno del Quebec rechazó participar en lo que veía como nueve personas, designadas desde las instituciones federales, decidiendo sobre el derecho a la autodeterminación del pueblo del Quebec" (Des Rosiers, 2000: 171-172).

Dos años después, el 20 de agosto de 1998, la Corte Suprema emitió su respuesta a través del Dictamen relativo a la Secesión del Quebec (Renvoi relatif à la sécession du Québec, 1998). De alto valor legal y pedagógico, la decisión fue -y continúa siendo- objeto de relevante análisis y debate y ha alcanzado un claro impacto internacional (Bérard, 2018). Con el fin de analizar y resumir las consecuencias de dicha decisión, debemos entender de dos maneras distintas el mecanismo legal promovido por la Corte Suprema: primero, los principios subyacentes de la Constitución sobre los que la Corte basa su razonamiento, y segundo, su aplicación en el contexto de la secesión.

\footnotetext{
${ }^{15}$ Traducción propia.

${ }^{16}$ Traducción propia.
} 
Dado que la Constitución no se pronunciaba sobre lo que estaba en juego en un proceso de secesión (Brouillet, 2010: 60-61), la Corte tuvo que construir su argumentación sobre fuentes no escritas de esta. El tribunal aseguró entonces que: "Tras la palabra escrita, existe un linaje histórico que se extiende décadas atrás y que asiste en la tarea de considerar los principios subyacentes de la Constitución. Estos principios informan y sostienen al texto constitucional: son supuestos vitales e implícitos sobre los que el texto está basado" (Renvoi relatif à la sécession du Québec, 1998: 49). La Corte continuó indicando que "federalismo, democracia, constitucionalismo y el Estado de Derecho, y el respeto de los derechos de la minoría son cuatro de los principios constitucionales fundamentales en Canadá, añadiendo que "funcionan en simbiosis" y que "[n]ingún principio en sí mismo puede definirse de manera aislada, ni puede, por la misma razón, triunfar sobre o excluir el cumplimiento de otro" (ibídem: 49). Estamos lidiando, por tanto, con normas de mismo peso, al llevar estas implícitas el principio sobredeterminante por el que se establece que ningún actor puede desestimar ninguno de dichos principios con el fin de garantizarse una posición de ventaja.

Tras un examen detallado de cada uno de esos cuatro principios (ibíd.: 4982), la Corte los aplicó al proceso secesionista del Quebec. Su razonamiento puede ser resumido de la siguiente manera: "El principio federalista, en conjunción con el principio democrático, dicta que el claro rechazo del orden constitucional existente y la clara expresión de la voluntad de perseguir la secesión por la población de una provincia daría lugar a la correspondiente obligación de todos los partidos de la Confederación de negociar los cambios constitucionales para responder ante tal voluntad" (ibíd.: 88). Ahora debemos establecer qué constituyen una pregunta clara, una respuesta clara y una negociación de buena fe (Taillon y Deschênes, 2012: 461), pero la Corte rechazó dar su opinión dado que considera esas cuestiones como de índole política: "La Corte no tiene un papel de supervisión sobre los aspectos políticos de las negociaciones constitucionales. De la misma manera, el ímpetu inicial de la negociación —una clara mayoría respecto a una pregunta clara a favor de la secesión- es, debidamente, el sujeto de una evaluación meramente política (Renvoi relatif à la sécession du Québec, 1998: 100).

El politólogo François Rocher extrae por su parte tres lecciones fundamentales de la decisión de la Corte Suprema: que (1) "un plan de secesión -o de enmendar el orden constitucional canadiense- [es] legítimo si [es] el fruto de la voluntad popular expresada en un referéndum libre de ambigüedades, tanto con respecto a la pregunta como al resultado obtenido a través de dicho referéndum"; que (2) "la legitimidad democrática del plan secesionista requiere, a cambio, una obligación constitucional de Canadá de negociar"; y que (3) "la Corte no tiene la intención [...] de dar una opinión adicional sobre estas cuestiones y [...] otorga a los actores políticos la responsabilidad de juzgar si las ambigüedades se han eliminado de acuerdo a su propia valoración de las circunstancias" (Rocher, 2018). En resumen, si un referéndum sobre la soberanía del Quebec obtuviese un claro apoyo popular, en respuesta a una pregunta clara, las autoridades políticas del Quebec y de Canadá tendrían la obligación constitucional de negociar de buena fe sobre la expresión de dicho resultado.

Con esa decisión, la Corte Suprema reconcilió por tanto intereses altamente divergentes. Su argumento, extraordinariamente matizado, ha sido en general bien recibido, tanto en Quebec como en el resto de Canadá. Además, todo apunta a que fue el resultado de un esfuerzo consciente por parte de la Corte: "Tras [el Dictamen relativo a la Secesión del Quebec], un notable número de autores destacaron la consideración tomada por la Corte Suprema para que su argumento fuese aceptado por los agentes legales del Quebec" (Mathieu y Taillon, 2015: 763-786). Por ejemplo, como subraya el jurista Frédéric Bérard: 
"El Dictamen relativo a la Secesión del Quebec es, a ojos de muchos, una respuesta inspiradora y meticulosamente matizada de las complejas consideraciones involucradas en la dinámica secesionista. Al confirmar la simbiosis entre democracia, Estado de Derecho, constitucionalismo, protección de las minorías y federalismo, muchos podrían argumentar que, en varios aspectos, la Corte Suprema de Canadá consiguió cortar un nudo gordiano que había sido hasta entonces imposible de desatar" (Bérard, 2018) $)^{17}$.

El politólogo François Rocher y la jurista Elisenda Casanas Adam se centran en la recepción de los argumentos de la Corte Suprema, tanto en Quebec como en la Canadá inglesa, así como en el mantenimiento de la neutralidad como árbitro constitucional:

"Así, [el Dictamen] irrumpió como el fruto del razonamiento equilibrado, manteniendo a su vez la legitimidad del poder judicial. La Corte Suprema tuvo éxito en la difícil gesta de declarar que la secesión unilateral del Quebec era ilegal mientras abría la posibilidad a un proceso que, teóricamente, podría desembocar en su independencia tras unas negociaciones de buena fe. Ambas partes podrían extraer de la Decisión argumentos que reforzaran su posición. El papel de la Corte como árbitro no fue objeto de debate" (Rocher y Casanas Adams, 2016: 906) ${ }^{18}$.

2.1.2. La Ley de Claridad y la declaración del Parlamento Federal de que era tanto parte como juez en disputas constitucionales

Ante la sutileza y la apertura de la Decisión de la Corte Suprema, el Gobierno de Canadá recurrió al Parlamento Federal para dar efecto a esa decisión. En palabras de Patrick Taillon: "No habiendo convencido del todo a la Corte Suprema de su defensa basada en el Estado de Derecho, las autoridades federales reaccionaron ante la opinión de la Corte promulgando nueva legislación" (Taillon, 2014: 13, 1516) $)^{19}$. A través de dicha ley (Loi donnant effet à l'exigence de clarté formulée par la Cour suprême du Canada dans son avis sur le Renvoi sur la sécession du Québec, 2000), el Parlamento Federal declaró que era tanto parte como árbitro de disputas constitucionales. Considerando que "la Cámara de los Comunes, como única institución política elegida para representar a todos los canadienses, tiene un papel importante en identificar qué constituye una pregunta clara y una clara mayoría suficiente para que el Gobierno de Canadá inicie negociaciones en relación a la secesión de una provincia de Canadá" (ibídem: preámbulo), el Parlamento adoptó una ley otorgando a la Cámara el poder de determinar, anteriormente al referéndum, si la pregunta es clara (ibíd.: s. 1), y, posteriormente al referéndum, si se ha obtenido una mayoría clara (ibíd.: s. 2).

Surgen al menos dos problemas con dicha ley: (1) el papel de la Cámara de los Comunes como árbitro, dado que su neutralidad puede ser cuestionada, y (2) la verificación a posteriori de la claridad del resultado del referéndum. Primero, con respecto al rol esquizofrénico de la Cámara de los Comunes, es altamente problemático garantizar total y únicamente el derecho absoluto y discrecional de juzgar la claridad de la pregunta y el resultado de un referéndum a una institución política federal. Como dice el jurista Stephen Tierney (2012: 318), "la Corte Suprema de Canadá confirmó que la claridad de la pregunta debía ser determinada por 'los actores políticos'. La Corte no indicó, sin embargo, que dicha cuestión debiera ser

\footnotetext{
17 Traducción propia.

18 Traducción propia.

${ }^{19}$ Traducción propia.
} 
resuelta exclusivamente por actores a nivel federal". En este sentido, compartimos la posición de que "[m]ientras la Cámara de los Comunes puede, sin lugar a dudas, expresar una determinada opinión política, no tiene, de ninguna manera, la competencia constitucional de tomar una decisión unilateral o emitir un fallo sobre dicha cuestión" (Taillon, 2014: 22) ${ }^{20}$.

Por otro lado, la evaluación a posteriori de la claridad del resultado del referéndum es problemática no solo por la ambigüedad que supone (ibídem: 36), sino también, y por encima de todo, por el recelo que despierta en lo que respecta al principio democrático. Con tal mecanismo de verificación a posteriori, "las autoridades políticas federales consiguen tanto cambiar las reglas del juego democrático durante el propio juego, apelando a una ruptura con la norma convencional de la mitad más uno, como garantizarse, al mismo tiempo, una capacidad extraordinaria de reescribir, o por lo menos clarificar, las reglas del juego una vez se haya celebrado el referéndum" (ibíd.: $37-38$ ) ${ }^{21}$. Por tanto, a través de esta ley, la cual se suponía que daba efecto al requisito de claridad, tal y como demandaba la opinión de la Corte Suprema de Canadá en el Dictamen relativo a la Secesión del Quebec, el Parlamento Federal, al contrario, ideó un mecanismo legislativo que a su juicio podía decretar — unilateral y arbitrariamente- la claridad a priori de la pregunta del referéndum y la claridad a posteriori de su resultado. En este sentido, la Ley de Claridad "es destacable por su mala fe, obviamente en contradicción con lo establecido por la Corte" (Bérard, 2016: 262) ${ }^{22}$ y por los principios constitucionales subyacentes.

Por estas razones, estamos profundamente de acuerdo con Patrick Taillon cuando utiliza la expresión "de la claridad a la arbitrariedad" para describir los efectos de la Ley de Claridad. Así mismo, en respuesta a dicha ley — cuyos propósitos democráticos nos parecen más que cuestionables-, la Asamblea Nacional del Quebec adoptó la Ley relativa al Ejercicio de los Derechos y Prerrogativas Fundamentales del Pueblo de Quebec y del Estado de Quebec (Loi sur l'exercice des droits fondamentaux et des prérogatives du peuple québécois et de l'État du Québec, 2001). Esta ley reconoce la importancia del Dictamen relativo a la Secesión del Quebec y denuncia la "política del Gobierno federal diseñada para cuestionar la legitimidad, integridad y operación eficiente de sus instituciones democráticas nacionales", particularmente a través de la Ley de Claridad (ibídem: preámbulo). Las autoridades políticas del Quebec, por tanto, prefirieron responder de manera política a la Ley de Claridad al decretar una ley en Quebec en vez de disputar la ley federal en los tribunales.

Sin embargo, la ley promovida en Quebec no se ha librado de crítica. Adoptada por la Asamblea Nacional del Quebec, afirma que "[e]l pueblo del Quebec, actuando a través de sus propias instituciones políticas, podrá determinar autónomamente el modo en que ejercer su derecho a elegir el régimen político y el estatus legal del Quebec" (ibíd.: s. 3), sin referirse a la obligación constitucional de negociar. La ley también establece que, una vez se celebre el referéndum, "la opción ganadora es la opción que obtiene la mayoría de los votos válidos, es decir, el $50 \%$ de los votos válidos emitidos más uno" (ibíd.: s. 4), puesto que ese porcentaje es considerado suficiente para asegurar el requisito de claridad del resultado.

Por tanto, aunque es cierto que tanto las autoridades políticas federales como las del Quebec recibieron favorablemente el Dictamen relativo a la Secesión del Quebec, ambas adoptaron legislación diseñada para darle efecto en la cual

\footnotetext{
${ }^{20}$ Traducción propia.

21 Traducción propia.

22 Traducción propia.
} 
ofrecían interpretaciones muy distintas, demostrando la falta de consenso sobre los requisitos que deben ser cumplidos para que Quebec pueda declarar su independencia. En este sentido, el activismo federal de las instituciones posterior al referéndum de 1995 cambió el debate constitucional y levantó otra serie de cuestiones.

\subsection{La evolución contemporánea del debate y cuestiones en suspenso}

El Dictamen relativo a la Secesión del Quebec fue incuestionablemente un punto de inflexión en el proceso soberanista del Quebec. Para empezar, resolvió un par de cuestiones primordiales, particularmente la cuestión de la capacidad del Quebec de separarse del resto de Canadá siempre y cuando se cumplieran ciertas condiciones: una pregunta clara, una respuesta clara y una negociación previa. Sin embargo, el Dictamen también hizo emerger nuevas cuestiones, incluyendo la que discutiremos en la próxima sección, (2.1.1) relativa al umbral de la mayoría popular requerida para que Quebec declare su independencia, y en la siguiente, (2.2.2) relativa a la ambigüedad procesal en cuanto a la obligación de negociar y al proceso de control de constitucionalidad pertinente.

2.2.1. El umbral de la mayoría popular requerida para que Quebec declare su independencia

La Corte Suprema discute el concepto de la mayoría clara en extensión en su decisión, dado que la expresión de tal mayoría debe ser el punto de partida de un proceso secesionista: "un voto mayoritario claro en Quebec en respuesta a una pregunta clara a favor de la secesión conferiría una legitimidad democrática a la iniciativa secesionista que todos los demás participantes de la Confederación deberían reconocer" (Renvoi relatif à la sécession du Québec, 1998: 150). Al no esclarecer explícitamente la forma que debería tomar dicha mayoría (ibídem: 100), la Corte deja en el aire este elemento fundamental. Consecuentemente, los poderes políticos de Ottawa (Loi donnant effet à l'exigence de clarté formulée par la Cour suprême du Canada dans son avis sur le Renvoi sur la sécession du Québec, 2000: s. 2) y del Quebec (Loi sur l'exercice des droits fondamentaux et des prérogatives du peuple québécois et de l'État du Québec, 2001, s. 4) se apresuraron a interceptar el balón y adoptar legislación — contradictoria- sobre la claridad del referéndum.

Es por ello que el debate evolucionó desde la incertidumbre de si Quebec tendría la capacidad de declarar su independencia a la mayoría necesaria para que eso fuera posible. La decisión de la Corte Suprema hace difícil saber si el precedente está en una mayoría clara en el sentido cuantitativo -en otras palabras, una mayoría reforzada-, o si la claridad debe interpretarse de acuerdo a criterios más cualitativos. No obstante, a pesar de esta ambigüedad, la Corte sí aportó un elemento importante de la respuesta en su decisión al señalar: "nos referimos a una mayoría 'clara' como una evaluación cualitativa. El resultado del referéndum, si es tomado como una expresión de la voluntad democrática, debe estar libre de ambigüedad tanto en la pregunta como en el apoyo conseguido" (Renvoi relatif à la sécession du Québec, 1998: 87).

De esta manera, la Corte señala el principio por el que, para ser clara, la mayoría no debería dejar lugar a dudas en cuanto a su expresión como voluntad democrática. De acuerdo a algunos autores, para estar libre de ambigüedad, "[l]as dimensiones cualitativas y cuantitativas serían, por tanto, simbióticas" (Bérard, 2016: 
$255)^{23}$ en el análisis de la claridad del resultado. Aunque este punto de vista sea defendible, debemos observar que, en su decisión, la Corte Suprema nunca menciona una clara mayoría en el sentido cuantitativo del término.

Sin embargo, los jueces eligen utilizar conscientemente el término claro, no reforzada ni cualificada, para referirse a la mayoría requerida (Rocher, 2018) ${ }^{24}$. Por esta razón, aunque los términos y la formulación utilizada por la Corte Suprema no excluyan expresamente la posibilidad de una clara mayoría en el sentido de que debería ser reforzada, una interpretación literal nos señala hacia otra dirección. Una mayoría clara, por tanto, sería una que tuviese el apoyo del $50 \%+1$ de la población (la cual es una mayoría absoluta) obtenido en un contexto en el que la libre expresión de la voluntad política del pueblo sea posible. La claridad de los resultados -en otras palabras, la ausencia de ambigüedad- sería entonces consecuencia del contexto social, político y legal en el cual la mayoría ha sido obtenida.

La mayoría clara en el sentido cualitativo a la que se refiere la Corte Suprema bien podría estar situada en una progresión de mayoría simple, mayoría absoluta y mayoría cualificada. Mientras una mayoría simple meramente requiere el mayor número de votos, una mayoría absoluta requiere la obtención del $50 \%+1$ de los votos. Tiene entonces la ventaja de dar el mismo peso político a cada voto durante la consulta. Finalmente, una mayoría cualificada requiere un apoyo mayor al $50 \%+1$ de los votos. Por ejemplo, el 55 o el $60 \%$ de los votos podrían ser los requeridos para que una opción pudiera ser considerada ganadora.

En ese sentido, una mayoría clara es más exigente que una mayoría simple o una mayoría absoluta porque está acompañada de un criterio cualitativo adicional, pero es más fácil de obtener que una mayoría reforzada. Los requisitos adicionales hacen posible, supuestamente, asegurar la dicha claridad de los resultados del referéndum, actuando como guardianes de la legitimidad de la expresión de la voluntad popular. Podríamos por tanto pensar que una alta participación en un referéndum libre de irregularidades en el que la población tiene que contestar una pregunta clara y en el que los gobiernos han acordado de antemano las reglas básicas del proceso, además de la obtención de una mayoría del $50 \%+1$, constituirían una mayoría clara. Debido a sus componentes constitutivos, este tendría más probabilidades de respetar los principios de federalismo, Estado de Derecho y democracia.

Por ello, dado que es la voluntad de tal mayoría clara de quebequenses a favor de la independencia la que obligaría a "las dos mayorías legítimas" (Renvoi relatif à la sécession du Québec, 1998: 93) de Canadá a negociar, parece indispensable que ambas se pongan de acuerdo en el significado de la claridad del referéndum. En otras palabras, el unilateralismo que hasta ahora ha caracterizado las acciones de los actores políticos tanto provinciales como federales con respecto al movimiento independentista del Quebec no parece ser ya realista. También parece que el proceso adoptado en Escocia deberá guiar la actuación de los actores implicados cuando exista un nuevo referéndum de soberanía: "la reciente aventura escocesa revela, irónicamente, el grado en el que Londres y Edimburgo parecen, al menos implícitamente, haber seguido in extenso las enseñanzas de la Corte Suprema de Canadá" (Rocher, 2016: 263) ${ }^{25}$.

Consecuentemente, los elementos que constituyen la clara mayoría requerida por la Corte Suprema deberían, en un escenario ideal, ser consolidados de manera consensuada entre Quebec y Ottawa, así como determinados y

\footnotetext{
${ }^{23}$ Traducción propia.

24 Traducción propia.

25 Traducción propia.
} 
conocidos previamente a la celebración del referéndum. Solo si se cumplen estas condiciones será posible que una clara mayoría de los quebequenses se exprese libremente, cumpliendo los principios subyacentes del federalismo y la democracia y estableciendo así la obligación a negociar.

\subsubsection{La ambigüedad procesal en torno a la obligación de negociar y al proceso} de control de constitucionalidad pertinente

En cuanto una mayoría clara de quebequeses expresen su voto a favor de la independencia, iniciando así el proceso secesionista, se da paso a una ambigüedad procesal: ¿qué pasos debe seguir el proceso? Una vez más, siguiendo el razonamiento de la Corte Suprema, podemos identificar al menos dos fases principales en el proceso: negociación, por parte de los actores políticos, de los términos de la secesión; y ratificación del acuerdo de secesión a través de una enmienda a la Constitución de Canadá.

Con respecto a la fase de negociación, la Corte no deja lugar a la ambigüedad en lo que respecta su obligatoriedad. Aunque rechaza la posibilidad de que Quebec pueda declarar su independencia unilateralmente, establece al mismo tiempo la obligación del resto de Canadá de negociar en el caso de que el referéndum fuese ganador. En palabras de la propia Corte, dicho referéndum "daría lugar a una obligación recíproca sobre todas las partes de la Confederación para negociar los cambios constitucionales que respondan a la voluntad expresada" (Renvoi relatif à la sécession du Québec, 1998: 88).

No es tanto el contenido de las negociaciones lo que importa ${ }^{26}$ sino los aspectos procesales implicados, es decir, el requerimiento de que las partes participen y el marco de las negociaciones. En relación a los actores participantes, existe un debate significativo sobre si el proceso debe ser bilateral o multilateral. En otras palabras, las negociaciones, ¿deberían llevarse a cabo exclusivamente entre los gobiernos de Quebec y Canadá, o deberían también incluir a las otras nueve provincias y territorios? La Corte no dice nada al respecto. En efecto, en un principio la Corte menciona que un referéndum ganador en Quebec "obligaría a las otras provincias y al Gobierno federal a reconocer y respetar la expresión de la voluntad democrática participando en las negociaciones" (ibídem: 88$)^{27}$, pero posteriormente añade que las discusiones deben darse entre "los representantes de dos mayorías legítimas, es decir, la mayoría clara de la población del Quebec y la mayoría clara de Canadá en su conjunto, cualquiera que esta sea" (ibíd.: 93) ${ }^{28}$. Es por tanto imposible determinar con certeza si la Corte opta por el bilateralismo o el multilateralismo en las negociaciones para alcanzar un acuerdo en cuanto a los términos de la secesión. El jurista Frédéric Bérard, sin embargo, plantea una cuestión interesante al afirmar que las otras provincias podrían delegar su papel en las negociaciones al Gobierno federal para facilitar así esa etapa del proceso" (Bérard, 2016: 257-258).

Resulta difícil predecir o estructurar la forma en la que las negociaciones se llevarían a cabo. A pesar del hecho de que han tomado lugar varias veces a lo largo de los años, "las conferencias constitucionales son una especie de objeto legal no identificado en la ley canadiense. Su iniciación, su conducta, sus participantes y su naturaleza vinculante permanecen objeto de preguntas nebulosas" (Guénette,

\footnotetext{
${ }^{26}$ En otras palabras, por ejemplo, los intereses relativos a "asuntos económicos, la deuda, los derechos de las minorías, los pueblos aborígenes y las fronteras territoriales", (Dion, 2016: 8), [traducción propia].

${ }_{27}$ Énfasis propio.

${ }^{28}$ Énfasis propio.
} 
$2015 \mathrm{~b}, 448)^{29}$. No obstante, sin querer ahondar en este tema, la Corte Suprema ha establecido que "[e]l proceso de negociación debe ser conducido en base a los principios constitucionales anteriormente descritos, los cuales deben informar las acciones de todos los participantes en el proceso de negociación" (Renvoi relatif à la sécession du Québec, 1998: 94).

Si los actores políticos llegasen a un acuerdo en cuanto a los términos de la secesión de Quebec $^{30}$, dicho acuerdo tendría que ser ratificado como enmienda formal a la Constitución para tomar efecto y por tanto cumplir con la legislación doméstica (Dion, 2018) ${ }^{31}$. La cuestión que entonces se plantea es simple: ¿qué procedimiento de control de constitucionalidad podría hacer oficial la secesión del Quebec? Dado que el proceso constituyente canadiense está extremadamente diversificado, existen un número de tesis contrapuestas que merecen nuestra atención.

Debido a que la Corte ya ha rechazado el unilateralismo con respecto a la secesión, los procedimientos de control de una ley ordinaria a nivel federal (Renvoi relatif à la sécession du Québec, 1998: 94) o provincial (ibídem: 45) deben ser excluidos. El procedimiento de revisión bilateral (ibíd.: 43) parece útil puesto que haría resonar la expresión "representantes de dos mayorías legítimas" (ibíd.: 93) que la Corte utiliza en el Dictamen relativo a la secesión del Quebec. Sin embargo, parece poco probable que el Gobierno federal y los gobiernos de las provincias anglófonas decidieran tomar este camino. El procedimiento "normal", conocido como 7/50 (Loi Constitutionnelle, 1982: s. 42), que requiere el consentimiento del Gobierno federal y de al menos siete provincias que reúnan al $50 \%$ de la población de Canadá, podría entonces aplicarse (Woehrling, 1995: 294). Este representaría el procedimiento residual del control de constitucionalidad. Se ha teorizado que podría haber un procedimiento de control implícito y sui generis único y específico para resolver el caso de la secesión (Tremblay, 1998: 423).

A la luz de lo aprendido recientemente en el Dictamen relativo a la Reforma del Senado de la Corte Suprema (Renvoi relatif à la réforme du Sénat, 2014), existen sin embargo buenas razones para pensar que el procedimiento preferido sería el de la unanimidad (Loi Constitutionnelle, 1982: s. 41). Aunque la secesión de una provincia no sea un asunto directamente tratado por la sección 41 de la Ley Constitucional de 1982, aquella tendría consecuencias estructurales relevantes en los asuntos tratados por dicha sección. Parece obvio que la secesión de la provincia del Quebec conllevaría un cambio en la composición de la Corte Suprema, en la cual debe haber un mínimo de tres jueces del Quebec. Posteriormente, por definición, la secesión de cualquier provincia tendría un impacto en las labores del vicegobernador. Lo mismo ocurre con las fórmulas de enmienda descritas en la Ley Constitucional de 1982 (Bérard, 2016: 258)32. En este sentido, incluso en la ausencia de consenso político o de la confirmación por parte de la Corte Suprema, debemos admitir que el proceso de revisión que requiere la unanimidad del Gobierno federal y de diez provincias sería, probablemente, el más aplicable para la secesión del Quebec bajo la ley canadiense.

En resumen, en la segunda parte de este artículo, hemos visto que el debate sobre la capacidad del Quebec de declarar su independencia es un asunto en el que no hay consenso bajo la ley constitucional canadiense, mientras que la posibilidad de que Quebec celebre un referéndum no presenta realmente ningún problema. En

\footnotetext{
${ }^{29}$ Traducción propia.

${ }^{30}$ Dicho acuerdo debería tener una forma similar que el Acuerdo del Lago Meech o el de Charlottetown.

${ }^{31}$ Traducción propia.

32 Traducción propia.
} 
realidad, fue la Corte Suprema la que puso fin a esta polémica, afirmando que la expresión de una mayoría clara de la población del Quebec, en respuesta a una pregunta igualmente clara, otorgaría la legitimidad necesaria para que los actores políticos del Quebec comenzaran el camino hacia la secesión. A pesar de la confirmación de la capacidad de la nación quebequense de alcanzar la secesión bajo ciertas condiciones, varias preguntas relativas al proceso de acceso a la independencia permanecen aún sin resolver. En concreto, podemos destacar el significado dado al concepto de mayoría clara, la manera en la que se debe dirigir el proceso de negociación, y el proceso de enmienda constitucional que haría efectiva la soberanía del Quebec.

3. Discusión y conclusión - Quebec y Cataluña: casos comparables significativos en contextos políticos y constitucionales muy diferentes

En esta última parte del análisis, tras haber explorado lo que creemos que son todas las preguntas y cuestiones relevantes relativas al proceso de acceso a la soberanía del Quebec, llevaremos a cabo una breve mirada comparativa entre Quebec y Cataluña, en la que sacaremos a la luz las diferencias fundamentes entre ambos procesos, así como las lecciones aprendidas en la experiencia del Quebec que podrían ser de utilidad desde el punto de vista catalán.

Si bien es cierto que existen varios paralelismos entre Quebec y Cataluña distinta lengua, autonomía gubernamental, población de unos ocho millones, una gran porción de su respectivo Estado, etc. - ambos casos están inmersos en contextos políticos y constitucionales muy diferentes. Precisamente estas diferencias pueden servir de base para explicar por qué el proceso de obtención de la independencia ha sido tanto más duro para Cataluña que para Quebec.

Para empezar, las constituciones que tienen efecto en Quebec y Cataluña son muy distintas, así como la cultura constitucional en sus respectivos estados. En Canadá, la naturaleza escrita y consuetudinaria combinada de la Constitución proporciona una gran flexibilidad a los tribunales y al poder político con respecto a su interpretación y aplicación. Dado que la Constitución no dice nada sobre la posibilidad de que una provincia demande su secesión, han sido los principios subyacentes de aquella los que han proporcionado la respuesta. Por el contrario, la Constitución española es escrita y superlegislativa y establece la unidad e indivisibilidad del Estado (Constitución Española, 1978, art. 2). Esta es una diferencia significativa entre la situación de Cataluña y la del Quebec, siendo para esta última más fácil iniciar un proceso de secesión. Sin embargo, volviendo al espíritu de la decisión de la Corte Suprema de Canadá, los principios de democracia y constitucionalismo no deben ser interpretados individualmente, abstrayendo al uno del otro, sino que deben ser analizados en un marco de conciliación. En este sentido, y de acuerdo a este argumento, el texto de la Constitución española no debe ser lo único que impida la expresión de la voluntad del pueblo catalán de alcanzar la secesión.

Una segunda diferencia entre las experiencias del Quebec y Cataluña la encontramos en la actitud de los poderes políticos centrales con respecto a los movimientos secesionistas. En Canadá, a pesar de que el Gobierno central ha mostrado cierto activismo desde el segundo referéndum, su actitud sigue estando lejos de la intransigencia del Gobierno español con respecto a los autonomistas e independentistas catalanes. Desde los repetidos recursos en el Tribunal Constitucional a la amenaza de utilizar la coerción para prevenir el avance de la causa soberanista, las acciones del Gobierno central denotan una completa intolerancia y un rechazo absoluto a la posibilidad de un escenario favorable a la secesión de Cataluña. De nuevo, las enseñanzas de la Corte Suprema de Canadá 
podrían informar y proveer de argumentos a los autonomistas e independentistas catalanes. En efecto, al imponer la necesidad de actuar de buena fe y con respecto a los principios constitucionales, así como la obligación a negociar la secesión en respuesta a la expresión de una mayoría clara a favor de esta, la Corte Suprema estableció principios cardinales que pueden servir de argumentos de peso en Cataluña con respecto al ejercicio de la democracia.

Esto nos lleva a una tercera y última diferencia crucial: la naturaleza justa, equitativa y ponderada de las decisiones de los tribunales constitucionales. Mientras que en Canadá la Corte Suprema ha reconocido que el orden legal canadiense hace posible la secesión de una provincia si se cumplen ciertas condiciones, en España el Tribunal Constitucional ha resuelto categóricamente que no es posible siquiera la celebración de un referéndum sobre dicha cuestión.

El efecto de la suma de estas tres diferencias fundamentales entre Quebec y Cataluña es que la última se enfrenta ahora a un impasse constitucional absoluto: ¿cómo puede consultar a sus ciudadanos sobre la secesión y actuar de acuerdo a un posible veredicto popular? El marco constitucional español y la intransigencia de los poderes políticos parecen obstáculos decisivos no solo respecto a la independencia de Cataluña, sino también, y sobre todo, con respecto a la expresión de cualquier voluntad democrática por parte del pueblo, lo que también debilita la reputación de España como espacio de democracia real.

Mientras tanto, Escocia -otro caso significativo comparable a los de las naciones quebequense y catalana - se plantea seriamente la posibilidad de celebrar un segundo referéndum sobre su independencia, en respuesta al brexit. Ante esta posibilidad, el Secretario de Estado de Escocia, quien es también miembro del Gobierno británico, declaró: "Conocemos el proceso a seguir para celebrar un referéndum. Debería darse el equivalente al anterior acuerdo de Edimburgo" (Carrell, 2017), confirmando así la importancia política y legal del precedente de 2014 sobre la cuestión.

El Reino Unido, de nuevo, da el ejemplo, tanto en sus bases legales como en las acciones de los actores políticos, con respecto a la manera de orquestar una reconciliación perfecta entre los principios constitucionales que una democracia multinacional debe representar en relación al deseo de autodeterminación de una nación minoritaria. Es en esas circunstancias en las que los ciudadanos de una nación podrán ser totalmente capaces de tomar decisiones políticas libres y de determinar su futuro constitucional, bajo los límites de los principios de la democracia y del Estado de Derecho.

En contraposición, cuando el orden constitucional y los actores políticos que en él participan optan por una dinámica y una estructura de dominación con respecto a una nación minoritaria que persigue la emancipación, la reconciliación entre los principios de la democracia, el Estado de Derecho y el federalismo resulta imposible. En contextos similares, el Estado multinacional pierde legitimidad dentro de las fronteras de la nación minoritaria, y dicha nación se vuelve libre de rechazar la camisa de fuerza constitucional (Tully, 1999: 1) que le niega su derecho inherente a la autodeterminación y la igualdad política.

Bibliografía

BEAUSÉJOUR, A. (2015), “Les référendums sur la souveraineté de l'Écosse et de la Catalogne. Le Renvoi relatif la sécession du Québec en comparaison", Tesis de maestría, Université de Montréal, Montréal.

BÉRARD, F. y BEAULAC, S. (2015), Droit à l'indépendance. Québec, Monténégro, Kosovo, Écosse, Catalogne, XYZ, Montréal. 
BÉRARD, F. (2016), "Du caractère lénifiant de la règle de droit interne en matière d'accession l'indépendance: les impacts du renvoi relatif la sécession du Québec". En: SEYMOUR, M. (Ed.), Repenser l'autodétermination interne, Thémis, Montréal.

BÉRARD, F. (2018), "De la réceptivité des enseignements de la Cour suprême l'échelle internationale: impacts et répercussions du Renvoi sur la sécession du Québec". En: TAILLON, P. y BINETTE, A. (Eds.), La démocratie référendaire dans les États plurinationaux, Presses de l'Université Laval, Québec.

BROUILLET, E. (2010), "Le fédéralisme et la Cour suprême du Canada: quelques réflexions sur le principe d'exclusivité des pouvoirs", Revue québécoise de droit constitutionnel, vol. 3 .

BRUN, H., TREMBLAY, G. y BROUILLET, E. (2014), Droit constitutionnel, $6^{e}$ éd., Éditions Yvon Blais, Cowansville.

CARRELL, S. (2017), "Theresa May lays down independence vote challenge to Nicola Sturgeon", The Guardian, 3 mars 2017, [www.theguardian.com/politics/2017/mar/03/theresa-may-lays-downindependence-vote-challenge-to-sturgeon?CMP=fb_gu].

DES ROSIERS, N. (2000), "From Quebec Veto to Quebec Secession: The Evolution of the Supreme Court of Canada on Quebec-Canada Disputes", Canadian Journal of Law \& Jurisprudence, vol. $13, \mathrm{n}^{\circ} 2$.

DION, S. (2016), "Le Renvoi relatif à la sécession du Québec: des suites positives pour tous", Revue québécoise de droit constitutionnel, vol. 6.

DION, S. (2018), "L'originalité canadienne en matière de référendums: l'expérience des référendums nationaux et d'autodétermination". En: TAILLON, $P$. y BINETTE, A. (Eds.), La démocratie référendaire dans les États plurinationaux, Presses de l'Université Laval, Québec.

DIRECTEUR GÉNÉRAL DES ÉLECTIONS DU QUÉBEC (2012), La consultation populaire au Canada et au Québec, $3^{\mathrm{e}}$ éd., [www.electionsquebec.qc.ca/documents/pdf/dge_6350.3_v.f.pdf].

DIRECTEUR GÉNERAL DES ÉLECTIONS DU QUÉBEC- (2017), Référendums, [www.electionsquebec.qc.ca/francais/provincial/resultatselectoraux/referendums.php].

DUMONT, H. y EL BEHROUMI, M. (2017), "La reconnaissance constitutionnelle du droit de demander la sécession dans les États plurinationaux". En: GAGNON, A.-G., y NOREAU, P. (Ed.) Constitutionnalisme, droits et diversité. Mélanges en l'honneur de José Woehrling, Thémis, Montréal.

GUÉNETTE, D. (2015a), "Le silence des textes constitutionnels canadiens Expression d'une Constitution encore inachevée", Les Cahiers de droit, vol. 56, $\mathrm{n}^{\mathrm{os}} 3-4$.

GUÉNETTE, D. (2015b), "La modification constitutionnelle au Canada - Quelle procédure pour quelle Constitution?", Revue belge de droit constitutionnel, vol. $21, n^{\circ} 4$.

GUÉNETTE, D. (2018), "Le référendum constitutionnel dans les sociétés fragmentées - L'expérience canadienne, son ambigüité et ses conséquences". En: TAILLON, P. y BINETTE, A. (Eds.), La démocratie référendaire dans les États plurinationaux, Presses de l'Université Laval, Québec.

HUTCHINSON, A. C. (2013), "Constitutional Change and Constitutional Amendment. A Canadian Conundrum". En CONTIADES, X. (Ed.), Engineering Constitutional Change. A Comparative Perspective on Europe, Canada and the USA, Routledge, New York.

MARQUIS, P. (1993), Les référendums au Canada: les conséquences d'un processus décisionnel populiste pour la démocratie représentative, [publications.gc.ca/Collection-R/LoPBdP/BP/bp328-f.htm]. 
MATHIEU, C. y TAILLON P. (2015), "Le fédéralisme comme principe matriciel dans l'interprétation de la procédure de modification constitutionnelle", Revue de droit de McGill, vol. 60, $\mathrm{n}^{\circ} 4$.

MATHIEU, F. y GUENETTE, D. (2018), "Empowering Minorities' Societal Culture within Multinational Federations". En: ARORA, B., STEYTLER, N. y SAXENA, R. (Eds.), The Value of Comparative Federalism. The Legacy of Ronald L. Watts.

PATTEN, A. (2002), "Democratic Secession from a Multinational State", Ethics, vol. $112, n^{\circ} 3$.

PELLETIER, B. (1996), La Modification Constitutionnelle au Canada, Carswell, Scarborough.

ROCHER, F. y CASANAS ADAMS, E. (2016), "L'encadrement juridique du droit de décider: la politique du confinement judiciaire en Catalogne et au Québec". En: TAILLON, P., BROUILLET, E. y BINETTE A. (Eds.) Un regard québécois sur le droit constitutionnel. Mélanges en l'honneur d'Henri Brun et de Guy Tremblay, Éditions Yvon Blais, Cowansville.

ROCHER, F. (2018), "Les incidences démocratiques de la nébuleuse obligation de clarité du Renvoi relatif à la sécession du Québec". En: TAILLON, P. y BINETTE, A. (Eds.), La démocratie référendaire dans les États plurinationaux, Presses de l'Université Laval, Québec.

TAILLON, P. (2014), "De la clarté l'arbitraire: Le contrôle de la question et des résultats référendaires par le Parlement canadien", Revista d'estudis autonòmics i federals, $\mathrm{n}^{\circ} 20$.

TAILLON, P. (2016), "Le référendum comme instrument de réforme paraconstitutionnelle au Québec et au Canada". En: SEYMOUR, M. (Ed.), Repenser l'autodétermination interne, Thémis, Montréal.

TAILLON, P. y DESCHÊNES, A. (2012), "Une voie inexplorée de renouvellement du fédéralisme canadien: l'obligation constitutionnelle de négocier des changements constitutionnels", Les Cahiers de droit, vol. 53, $n^{\circ} 3$.

TIERNEY, S. (2012), Constitutional Referendums, Oxford University Press, Oxford.

TREMBLAY, G. (1998), "La procédure implicite de modification de la Constitution du Canada pour le cas de la sécession du Québec", Revue du Barreau, vol. 58.

TULLY, J. (1999), "Liberté et dévoilement dans les sociétés multinationales", Globe. Revue internationale d'études québécoises, vol. $2, \mathrm{n}^{\circ} 2$.

WEINSTOCK, D. (2001), "Constitutionalizing the Right to Secede", Journal of Political Philosophy, vol. 9, $\mathrm{n}^{\circ} 2$.

WOEHRLING, J. (1995), "Les aspects juridiques d'une éventuelle sécession du Québec", Revue du Barreau canadien, vol. 74, $\mathrm{n}^{\circ} 2$.

Conferencias

BEAUD, O. (2017), "La sécession dans une fédération et son rapport avec le pacte", Conférence CREQC, Université du Québec à Montréal, 17 de enero 2017.

CAGIAO Y CONDE, J. (2016), "Pluralisme national et autogouvernement: vers une constitutionnalisation du droit d'autodétermination?", Conférence CRIDAQ, Université Laval, 3 de octubre 2016.

CRIDAQ y EURAC (2015), "La politique dans les sociétés fragmentées: Cohésion, reconnaissance, redistribution et sécession”, Bolzano, 14-27 de junio 2015.

Legislación

Constitución Española de 1978.

Constitutional Amendment Approval Act, 1996, R.S.B.C., c. 67.

Constitutional Referendum Act, 1992, R.S.A. c. 25.

Loi concernant les modifications constitutionnelles, L.C. 1996, c. 1.

Loi concernant les référendums sur la Constitution du Canada, L.C. 1992, c. 30. 
Loi constitutionnelle, L.C. 1982.

Loi donnant effet à l'exigence de clarté formulée par la Cour suprême du Canada dans son avis sur le Renvoi sur la sécession du Québec, L.C. 2000, c. 26.

Loi sur l'exercice des droits fondamentaux et des prérogatives du peuple québécois et de l'État du Québec, 2001, RLRQ, c. E-20.2.

Loi sur la consultation populaire, RLRQ c. C-64.1.

Loi sur la Cour suprême, L.R.C. 1985, c. S-26.

Jurisprudencia

CANADA, Haig c. Canada (Directeur général des élections), [1993] 2 R.C.S. 995.

CANADA, In re Initiative and Referendum Act, [1919] A.C. 935.

CANADA, Libman c. Québec (Procureur général), [1997] 3 R.C.S. 569.

CANADA, R. c. Nat Bell Liquors Ltd., [1922] 2 A.C. 128.

CANADA, Renvoi relatif à la réforme du Sénat, [2014] 1 R.C.S. 704

CANADA, Renvoi relatif à la sécession du Québec, [1998] 2 R.C.S. 217.

ESPAÑA, S.T.C. 31/2015, BOE no 64, p. 190.

ESPAÑA, S.T.C. 32/2015, BOE no 64, p. 213.

QUÉBEC, Boucher c. Mediacom, [1980] C.S. 481.

QUÉBEC, Boucher c. Mediacom, Conseil du référendum, 16 mayo 1980.

Documentos oficiales

Agreement between the United Kingdom Government and the Scottish Government on a referendum on independence for Scotland, 15 de octubre 2012, [www.gov.scot/Resource/0040/00404789.pdf].

CANADA, CHAMBRES DES COMMUNES, Débats de la Chambre des communes, 29 de noviembre 1995. 